\title{
Aesthetic Revolution and the Contemporary Construction of Utopia* $^{*}$
}

\begin{abstract}
XIANG Li
Yunnan University, Kunming, China

When Utopia is re-discussed in the contemporary era, it is no longer just a question about the continued writing of a romantic poem, but a revolutionary political question. As it is the "presence" of "absence", the charm of Utopia lies in that it is not only distant otherness, but a kind of existence always touching the undercurrent of reality. In contemporary era, Utopia exists in the paradoxical form of dystopia. It is just in the review on Utopia that the political potential of art enables aesthetic Utopia re-enter its promising holy land as a new configuration of contemporary Utopia. However, the practice of aesthetic Utopia is not entirely poetic; on the contrary, there are always many fields which intertwine around and fight against each other between reality and expectations. Therefore, the aesthetic revolution chooses a more prudent way after the passionate release.

Keywords: Utopia, Political potential, Aesthetic Utopia, Aesthetic Revolution, Institutional Critique, Aesthetic Capitalism
\end{abstract}

This year (2016) is the 500th anniversary since Thomas Moore published Utopia. What a kind of image will Utopia, a world once full of envy and questioning, re-appear in front of people? Or how should we re-discuss Utopia in an age of anti-Utopia /dystopia/ post-Utopia? This is a very challenging problem faced by contemporary aesthetics.

In the era when aesthetics and art have become a kind of special capital, there is no doubt that in the conception and construction of the future society, aesthetic / art is not only the superstructure, but also the foundation. In a sense, it can be said that Marx's spatial metaphor of economic foundation and superstructure is likely to get extreme interpretation in the contemporary era. It is worth to be expected that when social change takes place in the form of aesthetics and art, Utopia will exist as a being to be existent.

\section{The Contemporary Image of Utopia}

Utopia is the existence between the illusion and the reality without unanimous conclusion that can be drawn. It is because of the faced generous praise and relentless ridicule that it is filled with special luster and breath. In the contemporary era, how will we inherit its lingering charm twining the dust of history? Undoubtedly, talking about Utopia in the present is no longer just a question of continued writing of a romantic poem, but a revolutionary political problem.

\footnotetext{
* Acknowledgements: This paper was funded by China National Fund of Social Sciences "The Research of Fundamental Problems of the Contemporary Aesthetic and Criticism Forms" (15ZDB023).

XIANG Li is a Professor in College of Chinese Language and Literature, Yunnan University. Her research field covers Marxism aesthetics and Aesthetic Anthropology.
} 
"Utopia" derived from the immortal works of About the Perfect State System and Utopia New Island written by British humanist Thomas Moore in 1516 during the European Renaissance. This word did not exist in the first, but was created based on the ancient Greek, referring to "the land of nowhere" or "never land"; that is, a world which does not exist, ${ }^{1}$ and actually, it is a world existing elsewhere and belonging to the future. Following Moore, Saint Simon, Irving and Fourier used "scientific discovery" to avoid using Utopia to indicate their own ideas about the world or inventions; at the time, Utopia was in a dualistic risk zone between science and fantasy. However, in the views of Marx and Engels, these so-called scientific concepts are still inevitably caught in fantasy and criticized. Fantasy even becomes that Utopia cannot discard, which is also the embarrassment Utopia is difficult to get rid of. However, the complexity of the problem is that equating Utopia with fantasy is precisely the utmost misunderstanding and slandering against Utopia. In fact, as it is well known that in a sense it can be said that what Marxism insists is a powerful Utopian spirit or revolutionary anthropology.

Then what kind of power does Utopia have? What is the relationship between Utopia and social change? What is the media and the practice mechanism putting Utopia into operation in the reality? This is an irreproachable question to re-discuss Utopia in our contemporary era. Although Utopia seems to be only elsewhere, as it is the "presence" of "absence", the charm of Utopia lies in that it is not only distant otherness, but a kind of existence always touching the undercurrent of reality. In the field of philosophy, Ernst Bloch extended and promoted Utopia into a category of philosophy with universal significance. Bloch inherited the Utopian spirit of Marxism, and further pointed out that Utopia is not a non-existent world, but a world that does not exist or only exists in part at present, but may exist in the future. It is Utopian philosophy that it can arouse and give birth to a new world turning into reality from its potential state. ${ }^{2}$ Although Jameson made comment in his Marxism and Form that Bloch's philosophy of hope is not a true Marxist philosophy but a revolutionary theology; however, the dawn, the light, the joy, the supreme goodness and the brightness called for by the hope genealogy is undoubtedly the other side leading the positive direction and worthy of arriving as for alienation, retrogression and dullness of the reality. Moreover, in the book, Bloch collected and described a variety of Utopia emerged in the history, such as social Utopia, technological Utopia, architecture Utopia, geographic Utopia and so on, and made certain exploration and elaboration of the Utopian historical form and practical significance, which provides a positive reference value for exploring the medium of Utopia and its practice mechanism.

If Utopia's embarrassment lies in its alienation and estrangement from reality, then how to re-link Utopia's imagination with reality is the first prerequisite to seek the "material basis" of Utopia. Undoubtedly, in the Western Marxist camp, aesthetic Utopia shines with the aesthetic and art as an important carrier and core of Utopia. For example, Lukacs explored the way for the overall liberation of mankind through a general "narrative Utopia"; Benjamin reconstructed "nostalgia Utopia" after the disappearance of the "halo" based on the mechanical reproduction era; Marcuse proposed "new sensibility" to restore the Utopian's negation. Marcuse's "aesthetic Utopia" and rebellious aesthetics not only inherited and developed Marx's aesthetic criticism in a radical way, but deviated from it, which reflected the revolutionary nature and contradiction of Western Marxist aesthetics to a large extent and can be further discussed.

\footnotetext{
1 Thomas Moore, Utopia, translated by Dai Liuling, Beijing: Commercial Press, 2016, "Preface".

2 Zhu Liyuan, Zhang Dexing, et al., Aesthetics in the 20th Century (I), Jiang Kongyang, Zhu Liyuan (editors): General History of Western Aesthetics, Shanghai: Shanghai Literature and Art Publishing House, 1999, p. 780.
} 
In the views of Marcuse, as a great rejection and rebellion of the existing world itself and as a way to freedom and liberation, art depends on the non-repression provided by the illusion and thus refuses to be assimilated by reality. It is through the change in the particular historical world in the works of art, that is through the transformation appeared in manifestation of the concrete content itself that art opens another dimension to the existing reality: the possible emancipatory dimension. Indeed, it is an illusion, but another reality is born out of the illusion. Moreover, only art itself is willing to be illusion, that is, only when the art is an unrealistic world rather than the established world, another new reality will be produced... The transcendence of art aims to reach a space with specific possibility but not reach a fictional and illusory kingdom." ${ }^{3}$ Here, Marcuse makes a better interpretation of the relationship between the art as an illusion and the reality: in the extreme form of illusion, art helps individuals break the imaginary illusion that the real life is always in a harmonious relationship besides, it places "great rejection" of illusion to the reality into the context of reality to re-link the two ends of the illusion and reality in the new dimension of aesthetic dimension, thus arousing people's attention to and practice in the treatment of modern civilization's chronic illness. However, Marcuse also sees that the fate of the absolute negativity and rebellion of art in the developed capitalist society: art is reduced to a mere form of commodity, and even alienated to a form to whitewash and strengthen the established ruling order. In the process, the art's great rejection to the society itself is rejected by the society, and then art maintains the false consciousness and commitment to real life. ${ }^{4}$ The aesthetic enlightenment function contained in art in the way of rebellion is dispelled in the careful ideological reproduction mechanism of capitalism, which means that the irrationality of attempting to transcend and transform reality in the way of illusion and radical resistance can only be proved to be an insuperable tragedy. However, what Marcuse more emphasizes is that the political potential of art still exists in the art itself, that is, in the aesthetic form itself. Moreover, in the existing social relations, the art is mainly self-disciplined and it is just through the self-discipline that art not only resists the existing relations, but also transcend them; only by the way can art be considered revolutionary. ${ }^{5}$ Therefore, when the rebellious, self-disciplined and illusory art cannot undertake the critical and revolutionary task, Marcuse, like other scholars of the Frankfurter school, is also deeply plunged into deep emotion of pessimism.

Adorno once surprisingly pointed out that "writing poetry is brutal after the event of Auschwitz"; it also makes Adorno maintain a cautious enough attitude towards Utopia. There is no doubt that when brutal memories of Auschwitz that cannot be buried are latent in reality in a variety of forms that cannot be predicted, it is destined art after the event of Auschwitz can only be "anti-art art" or negative art. Then art no longer promises happiness or maintains the so-called noble silence, but shows awakening pains and opens a long revolution. In the slogans of "going out of Utopia", "a sacrifice to Utopia" and "dystopia" lingering in ears, Utopia is covered by a huge shadow difficult to be stepped out of, but it will eventually be able to break through such a spell with some kind of power and "stop" before the "wall of death". Then, after the event in Auschwitz, how will writing a poem not be brutal and re-show its poetic nature? Is aesthetic Utopia a perfect system planning? Or as an unfinished Utopia, how will it develop? These questions collectively present the

\footnotetext{
${ }^{3}$ Herbert Marcuse, Dimension of Aesthetics, translated by Li Xiaobing, Guilin: Guangxi Normal University Press, 2001, p. 147.

${ }^{4}$ Herbert Marcuse, Aesthetic Dimension, translated by Li Xiaobing, Guilin: Guangxi Normal University Press, 2001, pp. 67, 113, 145 .

5 Herbert Marcuse, Aesthetic Dimension, translated by Li Xiaobing, Guilin: Guangxi Normal University Press, 2001, pp. 189-191.
} 
contemporary image of Utopia: it is no longer a different world jumping out of the black hole of reality, but a restless particle that rips apart ideologically well-woven illusions and then makes the social fault re-slide. In short, Utopia exists in the paradoxical form of dystopia, and it is just in the review of Utopia that the political potential implied by the art itself enables aesthetic Utopia re-enter the promising holy land as a new configuration of contemporary Utopia

\section{The Concept of Aesthetic Utopia}

In the past, perhaps we were obsessed with asking "what is beauty / art?", but nowadays, such a problem has long been replaced by "what is the function of beauty / art?" Especially, in the theory field of Marxist, aesthetics and art is the negation and sublation of alienation. It is not only exist for simple sensual pleasure, but also appear as a force of social change.

Anthropological studies have shown that aesthetic / art has never been an isolated existence, but has a multiple overlapping relationship with the existence of the political / power / order. For example, Levi-Strauss pointed out "bisectional representation" to explain the duality of art when discussing the relationship between art and society in the writings of Melancholy Tropics and Structural Anthropology; it means that the primitive art based on face painting symbolizes both the transition of human beings from nature to civilization, but also the hierarchical structure within society and it is regarded as an illusory form to regulate social relations. Moreover, Strauss also puts forward the concept of "unstable signifier" by referring to the linguistic theory of the relationship between the signifier and designatum. He also points out that the myth and artistic creation is rooted in the "unstable signifier", because it is in the "unstable signifier" that the art's imagines and symbolization of the social relations are produced and reproduced. ${ }^{6}$ In fact, the multiple representations of "unstable signifiers" are precisely the important ways in which ideology can be constructed, and it implies various strategies and dimensions of social relations reconstruction. In addition, politics as a kind of clustered social relations contains the social hierarchy and order. For example, Jacques Maquet makes analysis of the significance of politics for the African art work manufacturing and its sense of beauty; he pointed out that "politics is another context to make goods present conspicuous beauty. For example, the chief's scepter, the throne of the king, the mark of the ruler's authority when he appears before his subjects and the gorgeous clothes of the royal ministers all were-and still are until now-instruments of power. They express and reinforce the fact that the ruler overrides the subjects. In some cases, these goods are the power: to have the crown or the throne and to give the king a legal status...these instruments of power always have decorations with great aesthetics." 7 Therefore, politics and its implicit power penetrate in the social classification framework through the form of art and its secret operating mechanism, making the aesthetics and art as a special system form become a delicate way of carving social relations.

Art exists in a certain social network and shows a certain class nature. According to the existence basis and structure of art, American scholar Toni Flores distinguishes art mainly as the art of the autonomous group; the art of the ruled group (including the art of the lower-level group of the hierarchy society, the art in the "fourth world" and the art of the conquered group), the art of the ruling group (including the art of the upper classes in the hierarchy society; the art of the controller of the mass market); he also points out that art does not

\footnotetext{
${ }^{6}$ Jos Gilem Meggio, Levi-Strauss's Aesthetics, translated by Huai Yu, Tianjin: Tianjin People's Publishing House, 2003, pp. 3-48.

7 Jacques Maquet, Experience of Beauty — visual art in the eyes of an anthropologist, translated by Wu Shanshan and Wang Huiji. Xiongshi Book Publishing Co., Ltd. 2003, p. 101.
} 
exist in a false non-political context, but occupies a specific position in the chain of power. ${ }^{8}$ According to Bourdieu's view, it is because art is divided into different fields that it shows the nature of segmentation. However, it is only one of the dimensions about the political understanding of art; Floris further points out that "a variety of aesthetics and artistic phenomena have their material bases. Each kind of art uses the principle of proportion, the principle of comparison and the principle of repetition to combine its various components in the way of formulation and exists in the established 'grammar' of culture. In the process, the art has been given a variety of symbolic significance. Whether as for groups or individuals, art allows for interpretation and innovation, and each art has its particular social function and both allow for innovation and change." It can be seen that art has the "material basis" for its existence, but art is not thus confined to the field it occurs. For example, aesthetic resistance of the art of vulnerable groups itself contains unlimited political potential. In another example, Julius E. Lips, in The Savage Hits Back (1937), illustrated how non-Western artists and craftsmen depict the image of white people in their paintings and sculpture in numerous and varied manifestation ways from the seemingly bland description to the ridiculous satirical cartoons. It is the earlier criticism on colonialism. ${ }^{10}$ In addition, Raymond Firth also points out that it is no longer a novelty to make political speech play a particular role through the media of art. In the history, art has a purpose of inducing people to understand and transform the social order. He argues that the consequences caused by the "political art" cannot be easily assessed, such as Soviet realism or Chinese murals about peasant struggles. ${ }^{11}$ These studies provide important theoretical value and practical significance for the insight into contemporary aesthetic and artistic issues such as aesthetic resistance and aesthetic repair.

It can be seen that aesthetics and art are not embellishments or appendages of the real life. It is a kind of rehearsal of the future life by gathering and re-opening the relationship in real life and remodeling people's emotional structure. In Marx's views, different from the three ways of mastering the world by political economy, religion and spirit of practice, art masters the world in the ways of imagination, fantasy and emotion, thus implying the possible power in the future. It is also all the connotation and meaning of aesthetic Utopia. It aims to resist all kinds of social alienation phenomenon in the aesthetic and artistic way and tries to ultimately transform the world by transforming people's aesthetic concept. It is also in the sense that Marcuse declares: "aesthetics will become a social political science."12 Therefore, the meaning of aesthetic Utopia does not lie in imagination, but in the reconstruction based on criticism. Especially in the contemporary context of increasingly declining Utopian imagination, the focus of Utopian narration will no longer be an unexpected ending, but a subtle rhetorical strategy.

When the classical Marxist makes criticism on illusion of Utopia and Western Marxism expresses great enthusiasm to the aesthetic Utopia while falling into the pessimistic complex difficult to be got rid of, Jameson's Marxist cultural and political science attempts to reignite the hope of Utopia in a new height. In Jameson's views, in the face of the advent of a new political and economic "world system", the old-fashioned Marxist cultural paradigms is difficult to play its role." ${ }^{\prime 13}$ In other words, with the interactive construction of

\footnotetext{
8 Toni Flores, The Anthropology of Aesthetics, Dialectical Anthropology, vol. 10, (July), 1985, p. 34.

9 Toni Flores, The Anthropology of Aesthetics, Dialectical Anthropology, vol. 10, (July), 1985 , p. 35

${ }^{10}$ See Jeremy Coote and Anthony Shelton (eds.), Anthropology, Art, and Aesthetics, Oxford: Clarendon Press, 1992, pp. 21-22.

11 Raymond Firth, Art and Anthropology, in Jeremy Coote and Anthony Shelton (eds.), Anthropology, Art, and Aesthetics, Oxford: Clarendon Press, 1992, pp. 35-36.

${ }_{12}$ Herbert Marcuse, An Essay on Liberation, Boston, Beacon Press, 1969.

${ }^{13}$ Frederic Jameson, Political Unconsciousness, Wang Fengzhen, Chen Yongguo, Beijing: China Social Sciences Press, 1999 , p. 4.
} 
economic base and superstructure now, to just stay in disenchantment in the ideological level of consciousness is not enough, because the "effective ideology must also be Utopia". ${ }^{14}$ Therefore, Jameson emphasizes the collaboration of Utopia and ideology and believes that such collaboration is bound to produce real political and strategic consequences. Then how will the ideology be effective? Since the "ideology" was constructed initially as a "science" and then criticized as a "false consciousness" and until it can be presented as a constructing power, ideology has always been the strangest and the most fascinating magic in all the cultural criticism and reconstruction projects and performed its multiple edges and corners. In a sense, it can be said that the effectiveness of ideology is that it can look face to face with the existing ideology and create its own new ideology through an anti-use mechanism. In collaboration with this new ideology, aesthetic Utopia will really stand at the entrance to the illusion from the reality. However, aesthetics and art is not a free setting; on the one hand, it is weaving the latitude and longitude of the reality and future; on the other hand, it is also restricted as a variety of meticulous institutional frameworks. It only indicates that aesthetic Utopia is still a long revolution.

\section{Aesthetic Revolution and Contemporary Construction of Utopia}

In modern times, aesthetic Utopia has increasingly presented the necessity and significance of its existence as a new form of Utopia; however, its practice is not entirely poetic; on the contrary, there are always various intertwined and competing fields between the reality and the expectations; therefore, the aesthetic revolution will choose a more prudent approach after the release of passion.

The Slovenian philosopher Arlesi El-Avić makes an extremely wise proposal that the transformation of social reality and the construction of the future takes place in the form of aesthetic revolution; in other words, aesthetic is essentially political. In fact, the concept of aesthetic revolution was earlier proposed by Schiller in the Letters of Aesthetic Education. In the face of failure of the French Revolution and its carrying terror, Schiller called for using the aesthetic revolution to replace the political revolution. That is, he proposes to bridge the split and alienated human nature by the aesthetic and artistic perfection. In the late twentieth century, the French philosopher Jacques Ranciere made a deeper interpretation and extension of the connotation and mechanism of the aesthetic revolution. Aesthetic revolution is also a classic topic of Marxist aesthetics. However, in modern times, aesthetic revolution has a more diversified "material basis" and mechanism, and it is undoubtedly an exciting and forward-looking artistic revolution.

In the views of Adorno, art is a social reality and is a special social reality. "Precisely, the sociality of art is mainly because it stands at the opposite side of society, but the opposite art appears only when it becomes self-disciplined." 15 Therefore, rebellion and negativity becomes the essence of art (mainly referring to the modern art); it criticizes the society by virtue of the impulse and passion "to become art itself". Aesthetic and art creates a radical attitude resisting the alienated reality and the established social order in the self-discipline way and the strategy attempts to avoid the art to be occupied and institutionalized by the society. However, an absolute self-disciplined aesthetic is fundamentally still an aesthetic Utopia. Faced with the reality, Adorno also falls into more calm thinking and has to recognize the dilemma of art in the association with the society. "If the art abandons self-discipline, it will yield to the established order, but if art expects to stick to its range of self-discipline, it will also be assimilated in the past, doing nothing in its designated position at an idle

\footnotetext{
${ }^{14}$ Frey Derek Jameson, Political Unconsciousness, Wang Fengzhen, Chen Yongguo, Beijing: China Social Sciences Press, 1999, p. 273.

p. 15 Adorno, Theory of Aesthetics, translated by Wang Keping, Chengdu: Sichuan People's Publishing House, 1998, p. 386.
} 
end. ${ }^{16}$ On the basis, in the criticism of aesthetic system, Adorno shows surprising awakening and wisdom, but he is still caught in a sorrow of salvation. Benjamin is more optimistic and he believes that modern technology will become the way for different group in the community to express, create and disseminate their own sub-culture. Since then, cultural studies have increasingly developed into one of the most dynamic and creative academic trends in the international academic community. These studies focus on the study of contemporary popular culture, especially marginal culture and subculture excluded by mainstream culture, such as working-class subculture, feminine culture, cultural experience and identity in the daily life of the oppressed nations in the capitalist society as well as the underlying potential of resistance and its expression mechanisms. These objects are so complex and difficult to be located that it necessarily requires an interdisciplinary, transdisciplinary and even anti-disciplinary attitude and research method. ${ }^{17}$ In the inner anthropology, the ethnographic fieldwork and experimental writing which more and more becomes a strong attempt in contemporary theoretical exploration and innovation will no doubt provide a new condition and development opportunity for the study.

After the dialectical thinking about art's self-discipline and heteronomy, that how avant-garde art opens a new aesthetic field between artistic self-discipline and political performance becomes a practical problem. Ranciere actively discusses the realistic mechanism of such an aesthetic revolution and points out that "the ultimate contradiction of the politics of aesthetics today may lie in that by inventing new forms of aesthetic distance or anesthetic indifference, art can promote a new political sense community to be opposed to consensus." ${ }^{18}$ In his view, the political potential of art lies in the distribution of the sensible and reshaping the new emotional structure and sense community on this basis so as to fight against regulation and violence hidden behind the illusion of identity in the form of disagreement. This program gradually shows its power as a political art precisely because it emphasizes the consultation and interpenetration of self-discipline and heteronomy of art; then art becomes art not because it stands in the opposite of society, but because it presents the cracks between the aesthetic Utopia and the reality and the implied political nature. In Ranciere's views, "the main program of political art or critical art lies in the encounter of heterogeneous elements and the display of possible conflicts."19 Therefore, such cracks not only exist between reality and the future, but also exists in the heterogeneity of all time flow. He also believes that the collision of these heterogeneous elements as well as the cross border and mixing between high-level art and low-level art, between art and merchandise and between art and non-art itself is a kind of emotional politics, which will bring new distribution and configuration of the sensible. For example, Ranciere lists and analyzes dialectics of conflicts and its implied political aesthetics showed in the exhibitions such as "Background Noise", "Look: this is the world in the mind" and "Moving Pictures" and other show.

There is no doubt that the juxtaposition of heterogeneous elements can indeed stimulate a sensible politics; however, when ideology diffuses in a variety of ways that cannot be expected, heterogeneity is often encapsulated in the illusion of identity and diffused. On the basis of recognizing the fact that art is institutionalized and ideologized, Begel tries to reveal the occultation of various institutional factors and

\footnotetext{
16 Adorno, Theory of Aesthetics, translated by Wang Keping, Chengdu: Sichuan People's Publishing House, 1998, P. 406.

17 Luo Gang and Liu Xiangyu (editors), Cultural Studies Reader, Beijing: China Social Sciences Press, 2000, "Introduction", P.1.

18 Jacques Ranciere, Politics of Contemporary Art and Aesthetics, translated by Xie Zhuoting, Marxist Aesthetic Study, Vol. 18, No.2.

19 Jacques Ranciere, Politics of Contemporary Art and Aesthetics, translated by Xie Zhuoting, Marxist Aesthetic Study, Vol. 18, No.2.
} 
institutions and their operational mechanism on the real life and the motive and secret of the embezzlement of art from the perspective of the particularity of art itself and the necessity to intervene in real life. He also attaches great importance to the value and significance of the avant-garde's attack on the art system. However, he is also pessimistic about the re-institutionalized fate of the anti-institutionalization movement of the avant-garde. ${ }^{20}$ This is precisely the dilemma of avant-garde art, because if any anti-institutionalized discourse and behavior expects to make a difference, it will have to make use of the established social identification mechanism; however, the existing mechanism tends to be an indispensable strong medium and social filter of social identity. As various systematic institutions recognize, accept, sponsor and propagate "anti" art, they turn from resistance to acquiescence and reconciliation of the established system. Then it will be difficult for shock aesthetics to sustainably work, especially when such shock is exhausted in its institutionalization. The dilemma of the critique of the aesthetic system is manifested in that it opposes a certain system, but the opposition can only exist by depending on the system and must manifest itself through the system. This is simply because it is still just resistance in the system. On the one hand, it means that there is no aesthetics and art that can be completely divorced from the system, because "beauty" is, after all, a constructed existence; on the other hand, it is an unavoidable problem to talk about Utopia in the contemporary era that how to make "beauty" become a kind of constructable existence and pursue the new space for existence of aesthetics, art and Utopia while alienating from the existing system.

While looking face to face with institutions and deciphering the careful functioning mechanism of ideology, institutional critique ${ }^{21}$ comes into being as a special form of contemporary aesthetic criticism and becomes a way with practical analysis and construction on the relationship between art and ideology and how art as a kind of special ideology. In a sense, it can be said that the institutional critique is not only the rebellion and alienation of the established institution on the basis of making the ideology visible, but exploring the deep link and its possibility between the aesthetic / art and imaginary and historic progress in the conflict between the new and the old aesthetic / artistic system so as to find the new dimension of the aesthetic / art and social development. The aesthetic / artistic institution is about the construction and specification of the aesthetic and art in the concept and behavior. On the one hand, it provides the necessary living space and the field of production and reception for the aesthetic / art; on the other hand, it causes certain restrictions to reproduction of the aesthetic and art. It is precisely because of the duality of the aesthetic / artistic system that makes the art still needs to maintain its proper distance from the institutional field where it is while obtaining its real expression form. As Begel points out, the organic unity of the bourgeois art system makes art seem weak in intervening in reality. "If the artist creates art fragments that are not closed but open to complementary reactions, then it has the opportunity to reintegrate into social practice."22 Therefore, the "non-closed nature" and "fragment" of art aims to break the illusion of the ideological unity and find the new chance for social change in the uncertainty and sliding of signifier and designatum of Utopia.

In the alienation of art from reality, if Utopia exists in a revolutionary tragic form, then the aesthetic capitalism as the fine and ingenious form of aesthetic Utopia shall present the trend of normal construction,

\footnotetext{
${ }^{20}$ Peter Bigel, Avant-garde Theory, translated by Gao Jianping, Beijing: Commercial Press, 2005, pp. 122-124.

${ }^{21}$ Gerald Raunig and Gene Ray (editors): Art and Contemporary Criticism, Practice and Theory of Reinventing Institutional Critique, which combines the related theories of anthropology and system theory to make a deep discussion of the relationship between art criticism and social movement and social change.

22 Peter Bigel, Avant-garde Theory, translated by Gao Jianping, Beijing: Commercial Press, 2005, p. 43.
} 
because "aesthetic capitalism is a promise that promises that the better is coming." 23 In contemporary era, aesthetics and art has become a special kind of capital carrying the sacred function of leading to Utopia, which is another special form of capital after Bourdieu proposes cultural capital. It further focuses on how the aesthetic and art can be the "basis" of social development and change as an important dimension to indicate the "contemporary nature" of contemporary aesthetics. Aesthetic capitalism has become the main form and trend of social development, and one of its distinctive feature is that aesthetic and art has become the main driving force of economic growth. In other words, the aesthetic war has become the core of economic war in the industrial civilization. ${ }^{24}$ Aesthetic Capitalism edited by Peter Murphy and Edward de la Fuente makes an in-depth analysis on the cultural contradictions of capitalism, the new form and spirit of contemporary capitalism, the topological structure of the aesthetic capitalism, the architectural style of the aesthetic capitalist era and its implied new modernism, experience economy, the inner spirit of aesthetic capitalism and its relationship with social development and other issues; it has been an important work to discuss the West capitalist culture and new changes of aesthetics through a combination of sociology and anthropology. These studies once again prove that "aesthetics no longer just belongs to the superstructure, but also belongs to the foundation." 25 Similar with the political potential of aesthetics and art, it is a secret fact which is happening.

In contemporary era, aesthetics and art no longer diffuse the irreducible halo as a ritualistic presence, but as a poetic and reproducible political science and economics, it is also the new configuration and new form of contemporary aesthetics and art. Between reality and Utopia, interruption and gap still exist; however, in the eye contact between aesthetic and art and ideology, the aesthetic revolution has quietly occurred when it can be presented as a special form of ideology.

\section{References}

Adorno. (1998). Theory of Aesthetics (K. P. WANG, Trans.). Chengdu: Sichuan People's Publishing House.

Bigel, P. (2005). Avant-garde theory (J. P. GAO, Trans.). Beijing: Commercial Press.

Coote, J., \& Shelton, A. (Eds.). (1992). Anthropology, art, and aesthetics. Oxford: Clarendon Press.

Flores. T.( 1985). The anthropology of aesthetics, Dialectical Anthropology, 10(July).

Jameson, F. (1999). Political unconsciousness (F. Z. WANG \& Y. G. CHEN, Trans.). Beijing: China Social Sciences Press.

JIANG, K. Y., \& ZHU, L. Y. (Eds.). (1999). General history of western aesthetics. Shanghai: Shanghai Literature and Art Publishing House.

Jos Gilem, M. (2003). Levi-Strauss's aesthetics (H. YU, Trans.). Tianjin: Tianjin People's Publishing House.

LUO, G., \& LIU, X. Y. (Eds.). (2000). Cultural studies reader. Beijing: China Social Sciences Press.

Maquet, J. (2003). Experience of beauty—visual art in the eyes of an anthropologist (S. S. WU \& H. J. WANG, Trans.). Xiongshi Book Publishing Co., Ltd.

Marcuse, H. (1969). An essay on liberation. Boston: Beacon Press.

Marcuse, H. (2001). Dimension of aesthetics (X. B. LI, Trans.). Guilin: Guangxi Normal University Press.

Murphy, P., \& Fuente, E. de la (Eds.). (2014). Aesthetic capitalism. Leiden, Brill.

Ranciere, J. (2004). Politics of contemporary art and aesthetics (XIE, Z. T. Trans.). Marxist Aesthetic Study, 18(2).

Souli, L. A. (2013). Aesthetic capitalism-Industrialization of taste (Y. HUANG, Trans.). Shanghai: East China Normal University Press.

Thomas. (2016). Moore: Utopia (L. L. DAI, Trans.). Beijing: Commercial Press.

Welsh, W. (2002). Reconstruction of aesthetics (Y. LU \& Y. B. ZHANG, Trans.). Shanghai: Shanghai Translation Publishing House.

${ }^{23}$ Peter Murphy, Eduardo de la Fuente (eds.), Aesthetic Capitalism. Leiden, Brill, "Introduction”, 2014.

${ }^{24}$ Livy A Souli, Aesthetic Capitalism - Industrialization of Taste, translated by Huang Yan, Shanghai: East China Normal University Press, 2013.

${ }_{25}$ Wolfgang Welsh, Reconstruction of Aesthetics, translated by Lu Yang and Zhang Yanbing, Shanghai: Shanghai Translation Publishing House, 2002, P. 78-102, 110, 9. 